\title{
Examining the Relationship Between Enclosure Ratio of Street and Skyline's Complexity
}

\author{
Leila Akbarishahabi ${ }^{\top} 1$ \\ ${ }^{1}$ Asst. Prof. Dr., Department of Architecture and Urban Planning, Cappadocia Vocational School, Cappadocia University, \\ Nevșehir, Turkey. Email: leila.akbarishahabi@kapadokya.edu.tr
}

\begin{abstract}
Purpose

The urban design criteria significantly affect the visual quality of space. Enclosure and Complexity can be defined as two crucial urban design principles that affect the perceptibility and visual quality of space. This study aimed to offer an objective and perceptual evaluation method in assessing the street's enclosure ratio. In the study, the street's enclosure ratio was evaluated via the street skyline's complexity.
\end{abstract}

Design/Methodology/Approach

According to the study's hypothesis, as the street's enclosure ratio increases, the street skyline's complexity level decreases. For testing this hypothesis, the street images were selected from the London and Chicago cities. Firstly, the skylines of the streets were determined on images, and then, the fractal dimensions of skylines were calculated. Then, the street's enclosure ratio and the factors that affect street skyline's fractal dimension were measured with a defined measurement system. Subsequently, the relationship between the street's enclosure ratio and calculated street skyline's fractal dimensions was examined by regression analysis.

\section{Findings}

As a result, it was determined that there is an inverse relationship between the street's enclosure ratio and the street skyline's fractal dimensions. As the enclosure ratio increases, the complexity of the skyline decreases. The decrease in the complexity level of the skyline weakens the visual quality and perceptibility of the street.

\section{Research Limitations}

In this study, the perceptual evaluation of the street's enclosure ratio was examined with an objective method. This method can also be reinforced with a subjective evaluation and more precise results can be obtained.

\section{Social Implications}

The obtained results can provide important clues to increase the visual quality and perceptibility of the streets. In perceptible spaces with high visual quality, feelings such as liking, trust, belonging and comfort develop in people.

\section{Originality/Value}

The fractal approach as an objective method is used widely for perceptual evaluation of the complexity level in cities. However, it was determined that very few studies examined the street's enclosure ratio with the perceptual and objective evaluation method. Perceptual evaluations of the enclosure were generally made with subjective methods. This study offered an objective and perceptual evaluation approach for examining the street's enclosure ratio. 


\section{INTRODUCTION}

In urban design studies, "having sufficient knowledge about design principles and techniques" and "directing the relationships and interactions between people, spaces and events correctly" are among the important issues to be considered. The theoretical framework of urban design principles and urban residents' perceptual-cognitive skills should be correctly correlated (Altaban, 2013). In urban spaces, the relationship between space and person is important. Because the person perceives and defines the space when he relates to it, urban design principles should strengthen the interaction between the individual and space (Aslan \& Atik, 2015; Kalın \& Yllmaz, 2012; Lynch, 1981). The strong relationship between person and space causes an increase in the sense of belonging, thus increasing the urban life's quality. One of the critical components of urban life's quality is visual data, and the quality of these data affects the visual quality. The visual quality of the space is related to how the person perceives and evaluates the space. The first sensory interaction of the person with the space is visual by nature (Val et al., 2006). In the twentieth century, Le Corbusier and like-minded modern architects sought to eliminate the traditional structure of cities to increase automobile use and focus on the functionality of the city. Thus, cities turned into soulless spaces with poor visual quality and low perceptibility (Hall, 2014; Sussman \& Hollander, 2015). The visual quality of the space is greatly affected by the design criteria of the space. "Enclosure" and "Complexity" principles, which are defined as two important urban design principles, affect the perceptibility and visual quality of the space. The enclosure is defined by vertical elements such as buildings, walls, and trees surrounding the space. The enclosure ratio, known as the rate of building height to street width, must be in a correct ratio to increase perceptibility. If the street is too wide, the space will not be on human scale, so the urban space is not visually and socially accessible. "Complexity" is the balance between chaos and monotony, the harmony between order and disorder. Complexity is expressed as the quantity of data an individual can perceive in his visibility angle of the vista. This perceived complexity includes the number, variety, and invisible connections between visual elements. As the visual information increases, space becomes more perceptible away from the monotonous. As the complexity increases, the density of new information presented to the individual increases, but excessive information confuses the individual. Therefore, the individual prefers optimal complexity, free from monotony and chaos. The fractal method, which can measure the optimal complexity level, is widely used in urban studies as a perceptual and objective evaluation method. However, very few studies examine the enclosure ratio of streets with perceptual and objective evaluation methods. This study aims to investigate the enclosure ratio of the street perceptually and objectively over the complexity level of the street skyline. In the study, firstly, the urban design principles affecting the visual quality were defined, then the concepts of enclosure and 
Examining the Relationship Between Enclosure Ratio of Street and Skyline's Complexity

complexity were explained in detail. After that, studies examining the street skyline's complexity with the fractal method were examined. In the method section, the hypothesis was tested, and the results were interpreted and concluded as a result of the findings. The hypothesis and framework of the study are explained in Figure 1.

Figure 1. The hypothesis and framework of the study (Drawings by the Author)

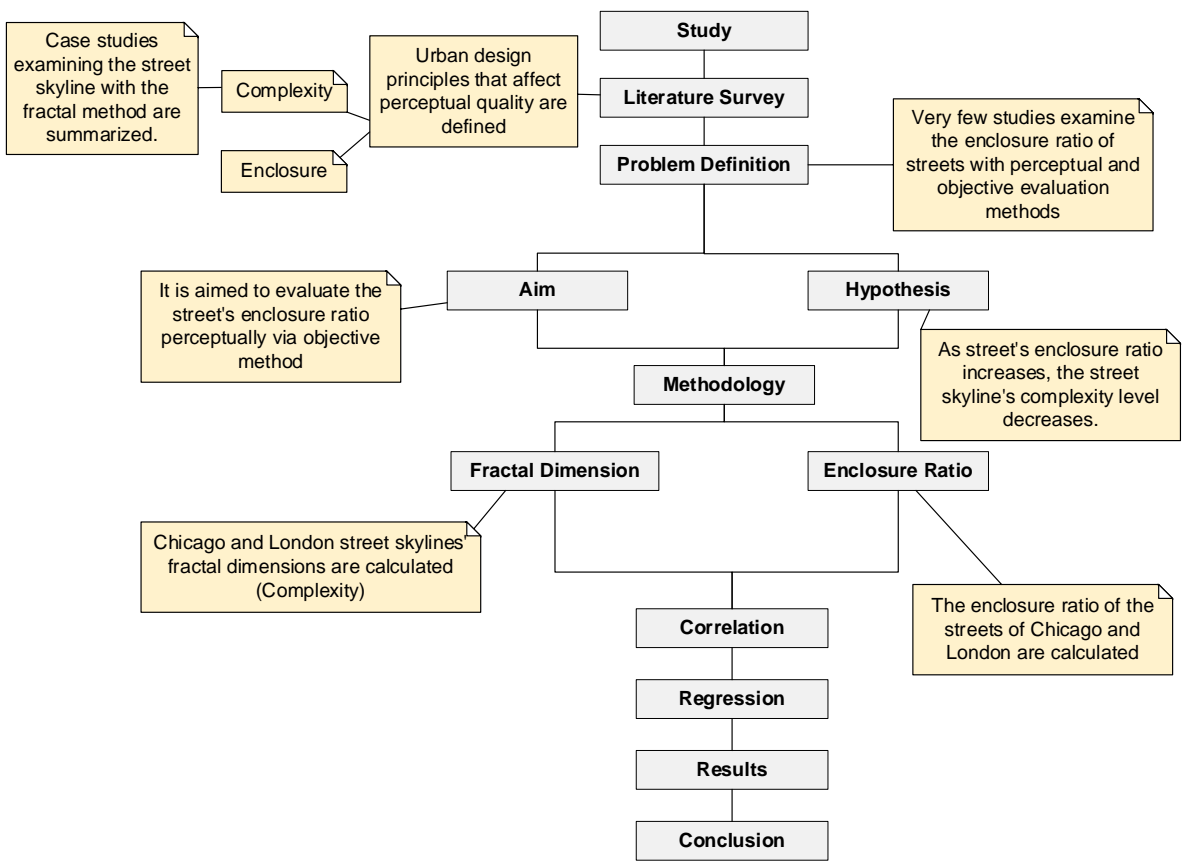

PERCEPTUAL QUALITY CRITERIA

Streets are among the most significant urban spaces, and the perceptibility of these spaces is critical in urban design studies. Therefore, many studies investigate the characteristics of these urban spaces related to their quality. Some of these studies were summarized in Table 1.

Table 1. Perceptual quality criteria of streets

\begin{tabular}{|c|l|}
\hline Researchers & \multicolumn{1}{|c|}{ Perceptual Quality Criteria } \\
\hline (J. Jacobs, 1961) & Complexity \\
\hline (Trancik, 1986) & Enclosure, continuity, building facade \\
\hline (Katz et al., 1996) & Coherence \\
\hline (Montgomery, 1998) & $\begin{array}{l}\text { Street greenery, transparency, human scale, } \\
\text { legibility, imageability }\end{array}$ \\
\hline (Carmona et al., 2003) & Enclosure \\
\hline (Ewing et al., 2005) & $\begin{array}{l}\text { Enclosure, complexity, coherence, legibility, } \\
\text { imageability, linkage, human scale, transparency }\end{array}$ \\
\hline (Pendola \& Gen, 2008) & $\begin{array}{l}\text { Perceptual feelings, scale and width of street, height } \\
\text { and facade of building, }\end{array}$ \\
\hline (Cooper \& Oskrochi, 2008) & Complexity \\
\hline (Xavier \& Portella, 2012) & Complexity \\
\hline
\end{tabular}

These criteria affect the users' willingness to stay on the streets or enjoy the place. They can also be defined as some of the basic perceptual features discussed in urban design studies (Gehl et al., 2006). Ewing \& Handy (2009) measured the subjective qualities of urban streets 
objectively in their research. They revealed five urban design principles that affect the quality of the street; complexity, enclosure, imageability, transparency and human scale (Ewing \& Handy, 2009). In many studies, the concept of enclosure and complexity are defined as critical components of visual quality that affects human perception (Berlyne, 1970; Blizek \& Berlyne, 1973; Carmona et al., 2003; Gehl, 2010; S. Kaplan et al., 1972; Nasar, 1984, 1994; Rapoport, 1977).

\section{Complexity}

Visual richness in urban spaces defines complexity. As one of the critical perceptual metrics, complexity describes a high-level phenomenon revealing from the connected and interacted subcomponent of a system and explains both dynamics and processes structurally (Spencer, 2009). Complexity is broadly classified into four categories: "structural complexity", "functional complexity", "structural hierarchical complexity" and "functional hierarchical complexity" (R. Kaplan et al., 1998). Structural hierarchical complexity is expressed as the quantity of data an individual can perceive in his visibility angle of the vista. This perceived complexity includes the number, variety, and invisible connections between visual elements. It is possible to associate the complexity of the street with four essential features: "layering at the edge of streets", "social diversity", "functional diversity" and "diversity in ages of building". The visual complexity of the street is affected by the varying forms, sizes, colors, materials and architectural details of the buildings, also the density of street furniture and landscape elements (Ewing \& Handy, 2009). The number and type of buildings, architectural details, decorations, landscape, and urban furniture affect the visual complexity of the urban spaces (Ewing \& Handy, 2009; Tveit et al., 2007). Perceived complexity in the space affects the individual's preferences (S. Kaplan et al., 1972; Oostendorp \& Berlyne, 1978), and the individual prefers the space with visual complexity (Blizek \& Berlyne, 1973; Denis \& Fernandez, 2014; Stamps, 2003, 2004). Despite the simplistic attitude of modern architecture in cities (or-or suggestions), traditional architecture with complexity (and-or-both suggestions) is recommended (Venturi, 1977). In cities consisting of similar elements with monotonous and homogeneous characters, the perception of complexity is lower, negatively affecting the urban identity. The relationship between the components is weak and ineffective, and space is not easily perceived (Alexander et al., 1977; Barratt, 1980; Zacharias, 2001). According to Berlyne (1970), maintaining the balance between chaos and monotony in the arrangement of urban elements creates the optimal level of complexity. It thus positively affects the perception of the individual (Berlyne, 1970). Berlyne (1970) explains the relationship between perceptual assessment and visual complexity as in Figure 2. 
Figure 2. The The relationship between perceptual assessment and visual complexity (Berlyne, 1970).

Figure 3. Number and differences (Drawings by the Author).

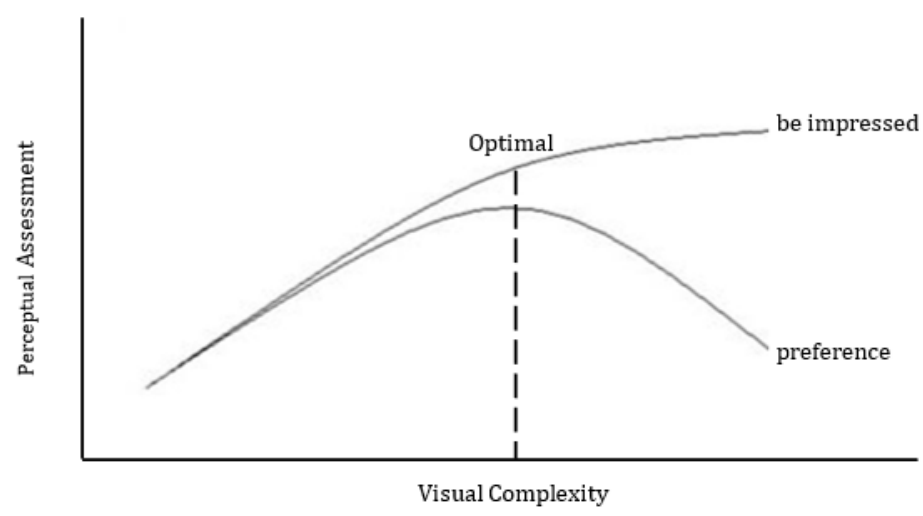

As complexity increases, the density of new information presented to the individual increases, and the individual is impressed. However, the individual prefers the optimal complexity and does not prefer the increasing visual complexity. The number (number of details) and shapes (differences in details) of the elements that make up the pattern affect the visual complexity (Berlyne, 1970).

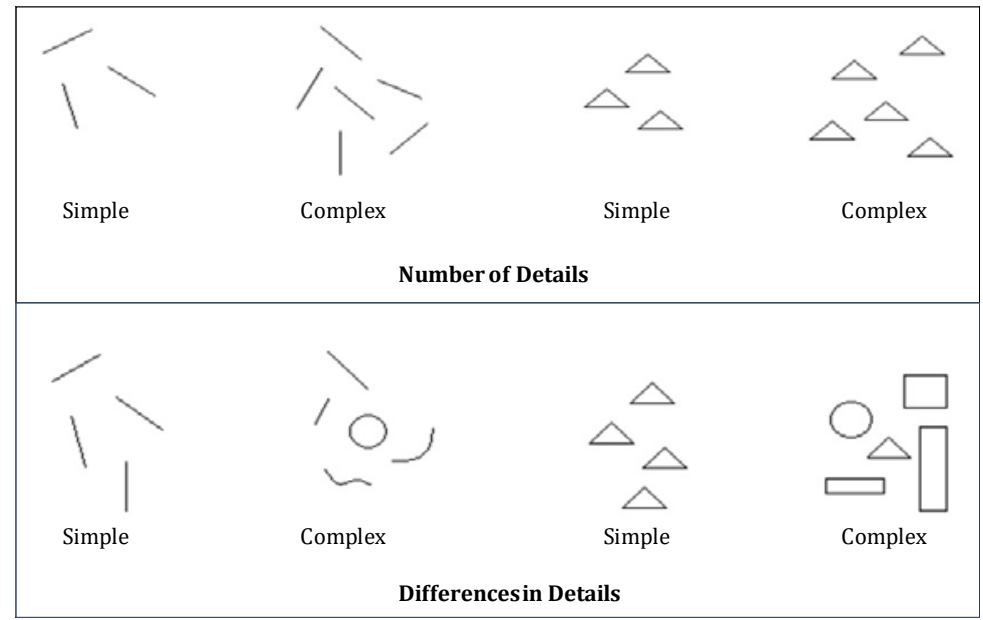

According to Rapoport (1990), the individual receives easily perceived information from the environment at a usable rate. Too little information causes sensory deprivation, too much information causes sensory overload (Rapoport, 1990). The increasing number of details and the formal differences of the details increase the visual complexity. Some variables that provide spatial complexity in urban spaces are explained as follows (Rapoport, 1977):

- Differences in building facades

- Use of different textures and materials

- Color variety

- Buildings of different heights

- Different windows

- Differences in the horizontal (in numbers)

- Differences in vertical

- Recesses and protrusions on building facades 
- Size variety

- Entrance doors in different positions

- Shades and fringes of different patterns

- Different stair designs

- Mobility of roofs

Streets are an essential element of a city and residential area, and the perceptibility of street views affects the residents' quality of life. Highquality designed streets help create urban vitality while also contributing to strengthening social interaction, increasing outdoor activities and improving people's health (Ye et al., 2018). Streets, defined as linear urban areas surrounded by buildings, are used for movement and activities. The critical parts of the visual elements of the streets can be defined as commercial signs along the street, the skyline, pavement, lighting, street furniture, landscape, and facades of buildings. These elements, which are visually in a hierarchical connection, represent the order of the street view. Two criteria are used to describe the order of street views: "visual complexity" and "visual diversity". Visual complexity expresses both the connections and diversity of visual components, while Visual diversity expresses only the diversity of visual components. Therefore, visual complexity is more significant than visual diversity because it can explain both the diversity and the connections of visual components (Gunawardena et al., 2015). Xavier and Portella (2012) evaluated the street's visual complexity through factors such as skyline, facade details, facade arrangements such as eaves, awnings, balconies, and color diversity. They found a positive relationship between the satisfaction level of individuals and the visual complexity on the street. The variables affecting the visual complexity of the street are listed as follows (Xavier \& Portella, 2012):

- Skyline: The symmetry of the skyline, the number of endpoints in the skyline, the symmetry of buildings, building heights, building widths, type of roofs

- Facade details: Architectural style, number of floors, components that make up the facade texture, revetments, and components

- Façade decorations: Door and window type and number, density

- Color diversity: Color variety and number on building facades

Studies show that three formal variables affect the visual complexity and perception of individuals on the street. These are skyline, façade details, and decorations (Burden, 1994; Ching, 2014; Groat, 1982; Stamps, 2000). According to A. Jacobs \& Appleyard (1987), narrow buildings on the street increase the complexity level of the street compared to wide buildings. It means that the increase in the number of buildings on the street causes increasing the street's visual complexity (A. Jacobs \& Appleyard, 1987). Visual complexity analyzes in urban spaces often focus on the complexity of building facades. However, in assessing visual quality, the complexity of the skyline has a critical role in individual satisfaction and preference (Heath et al., 2000; Nasar \& Terzano, 2010). On the street, the differences in the roof forms of the adjacent buildings, 
the density of the landscape, and furniture elements provide complexity on the skyline (Heath et al., 2000). There is a positive relationship between the level of individual's satisfaction and the street skyline's visual complexity, such as symmetry of the skyline, the number of peak points on the skyline, symmetry of buildings, building heights, building widths, mobility of roofs (Portella, 2007; Xavier \& Portella, 2012).

\section{Enclosure}

Enclosure is one of the basic principles of urban design. It varies by differences in the height of vertical elements such as buildings surrounding open space and the distance between vertical elements (Kahraman \& Cubukcu, 2017). Streets, defined as linear urban areas surrounded by buildings, walls, and landscape elements used for movement and activities. The enclosure of the street is defined by two variables: the height of vertical elements surrounding the street and street width. The ratio of building heights to street width is defined as the enclosure ratio of the street (Carmona et al., 2003; Ewing \& Handy, 2009). The degree of enclosure affects the viewpoints of people. The feeling of the enclosure is closely related to the continuity of the elements in the space (Ewing \& Handy, 2009). According to Carmona et al. (2003), as the height of the buildings on the street increases, the sky moves away, and the feeling of closure increases. In these streets, people's perception is negatively affected (building height/street width=4:1). Perceptually, the most positive sense of enclosure occurs on streets with an enclosure ratio of 1:1. Also, streets with an enclosure ratio of less than $1: 2$ have a low level of perceptibility (Carmona et al., 2003). According to Alexander et al. (1977), the street width should not be more than the building's height for the enclosure to affect human perception at a maximum and positive level. In addition, buildings not higher than four floors affect human perception positively by providing the connection between the upper floor of the building and the street (Alexander et al., 1977). A. Jacobs (1993) suggests that the ratio of heights of buildings to the width of street should be at least 1:2. In low-density urban areas, facades are less important in defining the street and trees play a critical role. Trees located on both sides of the street bring the height and width ratio to human scale. Trees support the perception of closure, especially in wide streets. Enclosure, which is at an optimal ratio, increases visual complexity in space by reducing the distance between components and people and creates a sense of confidence in the individual (A. Jacobs, 1993). According to Gehl (2010), to improve the visual quality and perceptibility of the streets, the street width should not be more than 10 meters, and the buildings surrounding the street should not be higher than 4-5 floors (Gehl, 2010).

\section{FRACTAL GEOMETRY}

The term "fractal" is derived from the Latin verb "frangere" which means broken and irregular. Along with this disorder and fragmentation, also 
objects that exhibit repetitive patterns are identified. A regular structural complexity emerges in these objects, with designs resembling themselves and appearing on increasingly more minor scales. This self-similarity is measured by the parameter of fractal dimension, which is the common feature of all fractal structures. The degree of irregularity in fractal structure quantifies by fractal dimension (D), and this quantitative value reveals the main features of its structure. It explains the degree of complexity and the number of details through scales. On 2-D surfaces, the fractal dimension value is calculated in the range of $1<\mathrm{D}<2$. As the complexity of the texture increases, the $\mathrm{D}$ value moves closer to 2 (Mandelbrot, 1982; Peitgen et al., 1993; Spencer, 2009). Fractal dimension refers to how the complexity of a form varies with the scale on which it is measured. The fractal dimension of an object expresses the space-to-full ratio by the self-similarity method, which becomes a bit more than a 1-D line, but a bit smaller than a 2-D surface. Fractal dimension measures include Hausdorff dimension and the box-counting dimension (Shen, 2002). Fractal dimensions of lines with different complexity show in Figure 4.

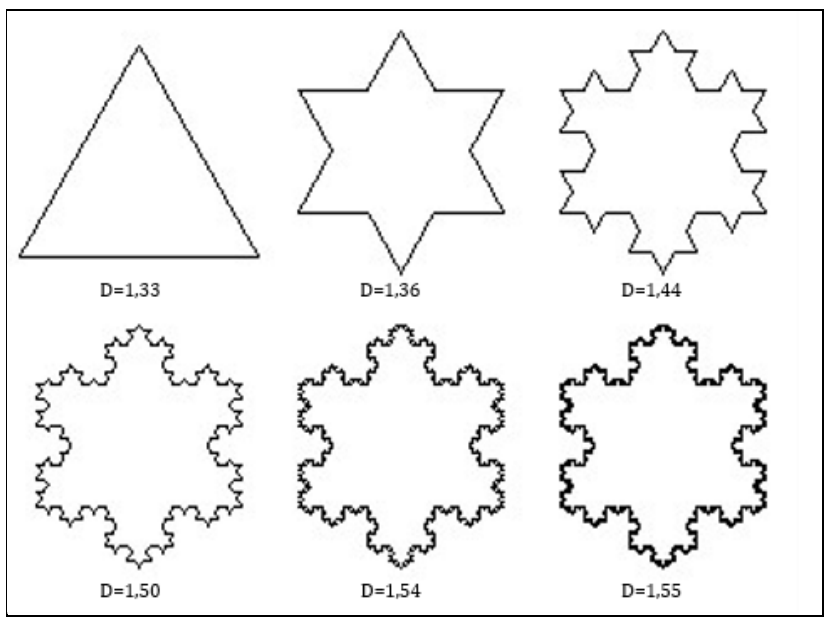

According to Figure 4, the fractal dimension approaches two as the complexity of the lines increases. The box-counting method based on a grid analysis is often used in fractal dimension calculation. In this approach, the image is covered with a grid made of squares of size $r$, and then how many boxes of the grid are covering part of the image is counted. Then the same thing is done by using smaller boxes (Jiang \& Liu, 2013). Fractal dimension is calculated through the following Equation (1):

Equation (1)

$$
D=\lim _{r \rightarrow 0}\left[\frac{\log N_{r}}{\log \frac{1}{r}}\right]
$$

In this equation, $\mathrm{N}$ is the number of boxes that contain something black, $\mathrm{r}$ is the length of the side of the squares, and D is the fractal dimension.
Figure 4. Fractal dimensions of lines with different complexity (Drawings by the Author). 
Fractal dimension increases when more boxes have information (Li et al., 2009). In the formal analysis of the space, the concept of "Golden ratio" is a classic and old approach, but fractal geometry offers a new approach. Repeats itself on an ever-reduced scale is the most significant feature of the fractals. Fractal objects are organized, complex, and hierarchically ordered structures with self-similarity parts. A fractal structure is the hidden harmony of nature founded on a form of scale symmetry, and we can find a series of scales at each scale of a complex object (Alexander et al., 1977; Batty \& Longley, 1994; Mandelbrot, 1982; Mesev et al., 1995; Salingaros, 1999).

\section{The Complexity of Street Skyline}

The legibility and perceptibility of urban vista affect the visual quality. Visual perception in urban spaces consists of recording the skyline of the space in memory as a mental image. Skylines are three-dimensional cityscapes that have a significant role in urban design studies. According to Bostancı \& Oral (2017), urban skylines can be evaluated in three classes: traditional skyline, modern skyline, and a combination of these two skylines. Skylines of traditional cities are perceptually complex and rich and clearer, and more legible than skylines of modern cities (Bostancl \& Oral, 2017). Different methods have been used in the objective evaluation of skylines that affect the aesthetics and visual quality of the city. Bostancı \& Ocakçı (2011) offered an objective method in the urban skylines' aesthetic and visual quality evaluation in their study conducted in Istanbul's various urban areas. In this study, the aesthetic value was transformed into numerical value by adapting the visual codes of the design components that form the city skyline. As an evaluation method, the entropy method was used in this study. The entropy method examines the amount of information of the coded data. In this approach, the aesthetic qualities of cities are examined in two groups as "Formal" and "Symbolic". While formal aesthetic qualities are defined by the concepts of "diversity", "harmony" and "clarity", symbolic qualities are defined with their "meaning" and "function" concepts. In this study, the coded information from different skylines was compared with each other. As a result, it was determined that the skylines representing the historical cityscape of Istanbul have more aesthetic value than other urban spaces. The study emphasized the usability of the entropy method in the aesthetic evaluation of the city skylines (Bostancı \& Ocakçi, 2011). In the research by Akdağ \& Bostancl (2013), a study was conducted on high rise buildings in the Central Business District of Istanbul to evaluate the aesthetic qualities of the city skyline. In this study, GIS models were made in the selected area, and skylines of the past, present, and future were extracted by visual analysis. The resulting skylines were finally analyzed by the Entropy method based on formal aesthetic properties. Then, the Entropy method used in the aesthetic evaluation of Skylines was adapted to GIS (Akdağ \& Bostancl, 2013). Some studies have focused on the concept of optimal complexity. In addition to the entropy method, 
the fractal method was also used in the urban skyline evaluation. In visual quality analysis, organized complexity has been defined as a fundamental characteristic that all perceivable and vibrant cities have in common (J. Jacobs, 1961; Salingaros, 2000). Many researchers have tried to find a simple visual order that counteracts the organically evolving complexity of urban, and they have attempted to impose Euclidean geometry to explain it. Today, however, cities that grow organically appear to have an optimal complexity, and their disorders appear to be a superficial view of a deeper order, and fractal geometry which is the language of nature and organic formation, is a tool that can explain this disorder mathematically (Batty \& Longley, 1994). The transition from order to disorder is defined by fractal geometry. In cities designed with a fractal approach, the individual's perception is positively affected, and the humanenvironment relationship is strengthened (Salingaros, 2010; Taylor, 2006). According to various studies, there is a positive relationship between individual judgment regarding visual quality and fractal dimension expressing the level of complexity (Cooper \& Oskrochi, 2008; Cutting \& Garvin, 1987). In Stamps (2002) study, the fractal dimension of the skylines of spaces consisting of buildings with different heights was calculated. Then, a comparison was made between the fractal dimension of the skylines and participant preferences. According to the study results, skylines with a high fractal dimension were preferred with a high ratio (Stamps, 2002). In the study conducted by Hagerhall et al. (2004), the relationship between the preferences of participants and the fractal dimension of the skyline was examined. As a result, it was determined that there is a positive relationship between individuals' preferences and fractal dimensions. The density of landscape elements caused fractal dimensions to be high. Also, the number of participants liking these images was high (Hagerhall et al., 2004). In Cooper's (2003) study, the fractal dimension of the street skyline was compared with the characteristics of the street. In the study, it was determined that the mobility of the roofs of the buildings, the intersection of the landscape with the skyline, and the level of enclosure of the street affect the fractal dimension of the skyline of the street. As a result, the mobility on the roofs of the buildings, the enclosure of the street and the density of the vegetation caused the fractal dimension of the skyline of the street to be high (Cooper, 2003). The study by Chalup et al. (2009) aimed to reveal the relationship between the complexity of the skyline and the physical features of the street. As a result, it has been determined that the intersection of the landscape elements on the street with the skyline causes the fractal dimension of the skyline to be high (Chalup et al., 2009).

\section{RESEARCH METHOD}

This study aims to evaluate the street's enclosure ratio through the street skyline's complexity with the perceptual and objective method. For this purpose, images of streets with different enclosure ratios were used from London and Chicago cities. There are two important reasons for choosing 
Examining the Relationship Between Enclosure Ratio of Street and Skyline's Complexity

sample cities: 1 . London streets have a traditional skyline type, and Chicago streets have a modern skyline type. In terms of the richness of the dataset, two cities with different street skylines types were preferred. 2. In this context, to test the hypothesis, street samples with various enclosure ratios between 1:2 and 4:1 were analyzed by creating a rich data set. Forty-two street images taken with "Google Instant Street View" from both cities were used in the analysis. The images were taken from the middle point of the streets on the vertical and horizontal axis $(+)$. While taking the images, attention was paid to ensure that parameters such as scale, resolution, zoom ratio, and angle of view were the same in all images.

\section{Dependent and Independent Variables}

In this section of the study, the factors that affect the street skyline's fractal dimension were determined as independent variables. The fractal dimension of the street skyline was also defined as the dependent variable. Dependent and independent variables are shown in Table 2.

Table 2. Dependent and independent variables

\begin{tabular}{|c|l|}
\hline Dependent variable & \multicolumn{1}{c|}{ Independent variables } \\
\hline \multirow{4}{*}{$\begin{array}{c}\text { Skyline's fractal } \\
\text { dimension }\end{array}$} & Number of buildings with different heights \\
\cline { 2 - 2 } & Number of peak points on building roofs \\
\cline { 2 - 2 } & Intersection of furniture elements with skyline \\
\cline { 2 - 2 } & Intersection of landscape elements with skyline \\
\cline { 2 - 2 } & Enclosure ratio of street \\
\hline
\end{tabular}

\section{Measurement of the independent variables}

In this section, the quantitative values of the independent variables were calculated. The measurements of independent variables as the characteristics were performed for each of the streets. The measurement system is given in Table 3 . The number of buildings with different heights is calculated by counting through the street images. For calculating the number of peak points on building roofs, breakpoints on building roofs are counted from street images. Since the mobility in traditional building roofs is high, this number can be more. Whether the landscape and furniture elements on the street intersect with the skyline is evaluated through the street images. For calculating the enclosure ratio of the street, the number of floors of the buildings is counted, and the number of floors is multiplied by 3 , assuming that the floor is the standard 3 meters, at the same time, the street width is measured with the ruler tool in the "Google Earth" program, the ratio of the obtained building height to the street width is used as the enclosure ratio of the street in the analysis. Average building height is used for streets with buildings of different heights. 
Table 3. The measurement system

\begin{tabular}{|c|l|}
\hline $\begin{array}{c}\text { Independent variables } \\
\text { Number of buildings } \\
\text { with different heights }\end{array}$ & $\begin{array}{l}\text { This variable was calculated by counting the number of } \\
\text { buildings with different heights through the images. }\end{array}$ \\
\hline $\begin{array}{c}\text { Number of peak points } \\
\text { on building roofs }\end{array}$ & $\begin{array}{l}\text { This variable was calculated by counting the number of } \\
\text { peak points on the building roofs through the images. }\end{array}$ \\
\hline $\begin{array}{c}\text { Intersection of furniture } \\
\text { elements with skyline }\end{array}$ & $\begin{array}{l}\text { This variable was evaluated whether the furniture } \\
\text { elements intersect with skyline in the images } \\
\text { (intersection =1, non-intersection =0) }\end{array}$ \\
\hline $\begin{array}{c}\text { Intersection of landscape } \\
\text { with skyline }\end{array}$ & $\begin{array}{l}\text { This variable was evaluated whether the elements of } \\
\text { landscapes intersect with the skyline in the images } \\
\text { (intersection =1, non-intersection =0) }\end{array}$ \\
\hline $\begin{array}{c}\text { Enclosure ratio of street } \\
\text { (Building height/ Street } \\
\text { width) }\end{array}$ & $\begin{array}{l}\text { "Street width" and "building height" were calculated } \\
\text { through the "Google Earth" program, and then the } \\
\text { enclosure ratio of the street was measured as the ratio of } \\
\text { building height to street width. }\end{array}$ \\
\hline
\end{tabular}

\section{Calculation of the dependent variable}

In this section of the study, the calculation method and values of fractal dimension of street skylines defined as dependent variables are explained. Primarily, the skyline of the streets was determined by Photoshop program for each image. The images were adjusted on the 2D plane, and attention has been paid that there is no deformation or clipping in determining the street skyline line. The fractal dimension of the street skyline was calculated by the box-counting method in "HarFa" program (Zmeškal et al., 2001). According to the research results, other software programs calculate the fractal dimension with a limited number of box sizes. Therefore, the HarFa program, which allows many calculations with all possible box sizes $(2,3,4,5, \ldots$, max $)$, was preferred. The pixel size of all images used in fractal dimension calculation kept the same. For preventing erroneous measurements, the fractal dimension of each street skyline was calculated 30 times, and the average value of these measurements was used in the analysis as the street skyline's fractal dimension (D). The street images, skylines, and fractal dimensions of street skylines were shown in Table 4.

Table 4. Street images, skylines, and the fractal dimensions

\begin{tabular}{|c|c|c|c|}
\hline \multicolumn{3}{|c|}{ Street images, skylines, and the fractal dimensions of street skylines } \\
\hline & & & \\
\hline $412 \mathrm{~N}$ Clark St. & $127 \mathrm{~W}$ Medison & $76 \mathrm{~W}$ Jackson & W Erie St. \\
\hline $\mathrm{D}=1,03$ & $\mathrm{D}=1,04$ & $\mathrm{D}=1,05$ & $\mathrm{D}_{\mathrm{s}}=1,06$ \\
\hline $\mathrm{N}$ & & & \\
\hline & & & \\
\hline & & & \\
\hline $\mathrm{S}$ Wacker St. & $65 \mathrm{E}$ Monroe St. & $100 \mathrm{~N}$ La salle St. & $\mathrm{N}$ La Salle St. \\
\hline $\mathrm{D}=1,07$ & $\mathrm{D}=1,08$ & $\mathrm{D}=1,10$ & $\mathrm{D}=1,10$ \\
\hline
\end{tabular}


Examining the Relationship Between Enclosure Ratio of Street and Skyline's Complexity

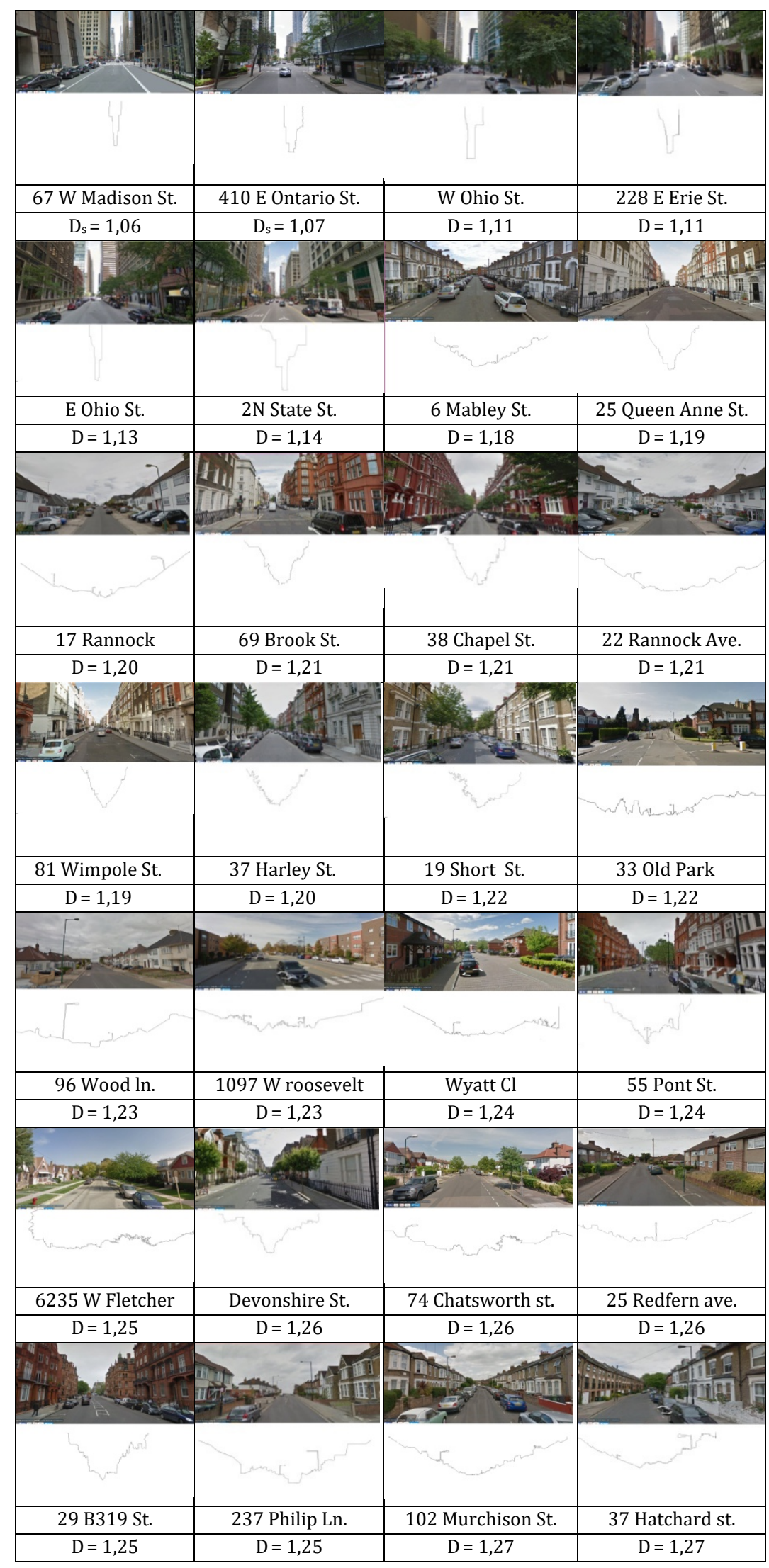




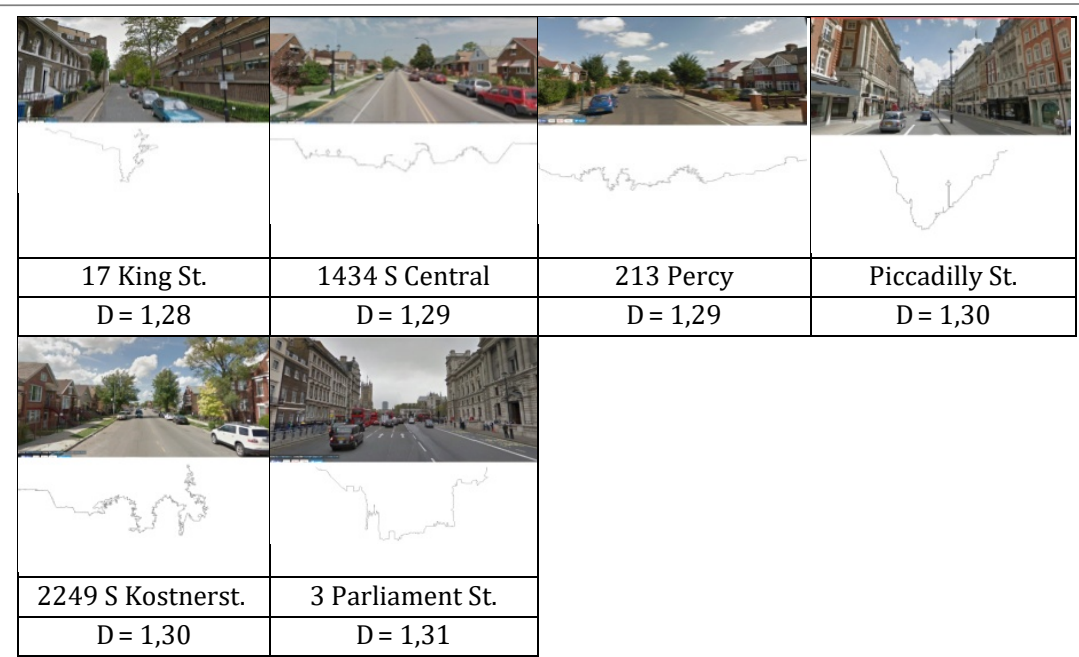

Descriptive statistical analysis of calculated fractal dimensions was given in Table 5. The minimum fractal dimension was calculated as 1,04, and the maximum value was 1,31 . The average of fractal dimensions was calculated as 1,193 . Also, the distribution plot of fractal dimensions obtained was shown in Figure 5.

Table 5. Descriptive statistics

\begin{tabular}{|c|c|c|c|c|c|}
\hline & Min. & Max. & Mean & $\begin{array}{c}\text { Std. } \\
\text { Deviation }\end{array}$ & Variance \\
\hline $\begin{array}{c}\text { Fractal Dimension } \\
\text { (D) }\end{array}$ & 1,040 & 1,310 & 1,193 &, 08365 &, 007 \\
\hline
\end{tabular}

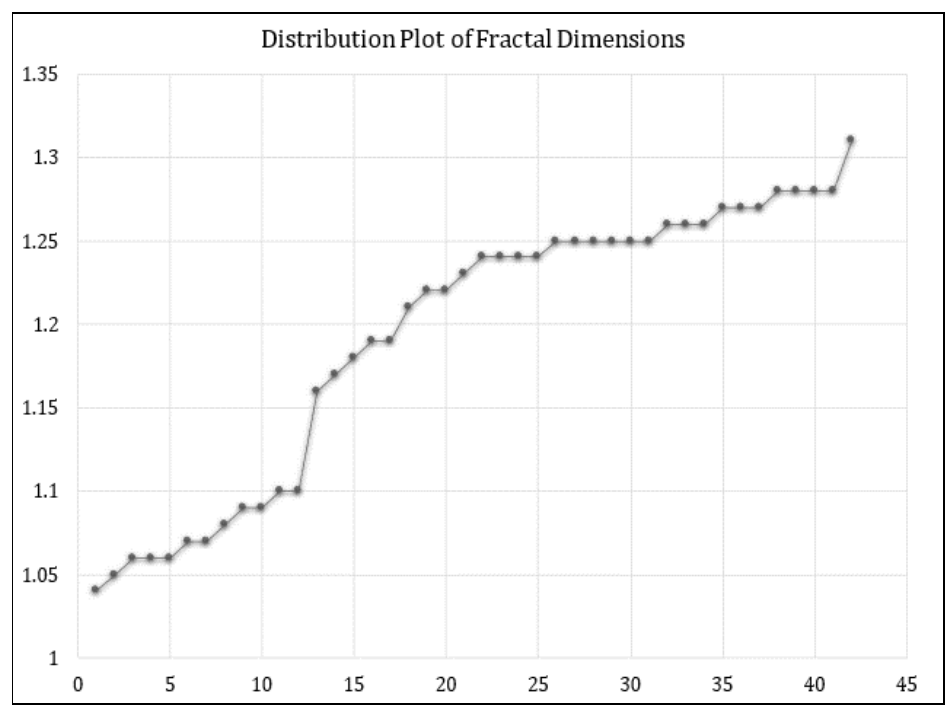

Figure 5. Distribution plot of fractal dimensions

\section{Evaluation of the Relationship Between Dependent and Independent Variables}

\section{Correlation analysis}

In this section of the study, Pearson's correlation analysis was performed between dependent and independent variables, considering having a normal distribution of the data. SPSS 26 program was used for statistical 
Examining the Relationship Between Enclosure Ratio of Street and Skyline's Complexity

analysis. In correlation analysis, the coefficients were examined at $\mathrm{p}$ $<0,01$ significance level. The coefficients obtained from the correlation analysis are shown in Table 6.

Table 6. The result of correlation analysis

\begin{tabular}{|c|c|c|c|c|c|c|c|}
\hline \multicolumn{8}{|c|}{ Correlation } \\
\hline & & 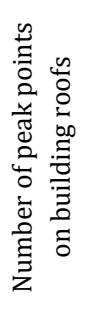 & 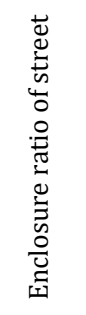 & 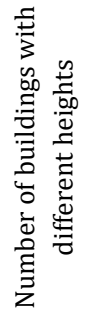 & 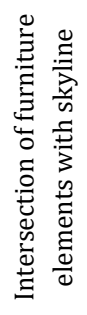 & 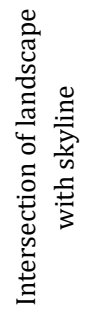 & 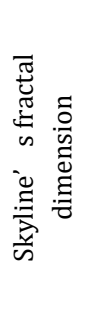 \\
\hline \multirow{3}{*}{$\begin{array}{l}\text { Number of peak } \\
\text { points on building } \\
\text { roofs }\end{array}$} & Pearson Correlation & 1,000 &,$- 644^{*}$ &, $606^{*}$ & $428^{*}$ & ,352 & ,648* \\
\hline & Sig. (2-tailed) & &, 000 &, 000 &, 005 &, 022 &, 000 \\
\hline & $\mathrm{N}$ & 42 & 42 & 42 & 42 & 42 & 42 \\
\hline \multirow{3}{*}{$\begin{array}{c}\text { Enclosure ratio of } \\
\text { street }\end{array}$} & Pearson Correlation &,$- 644^{*}$ & 1,000 &,$- 720^{*}$ &,$- 758^{*}$ &,$- 586^{*}$ &,$- 816^{*}$ \\
\hline & Sig. (2-tailed) &, 000 & & ,000 &, 000 & ,000 & ,000 \\
\hline & $\mathrm{N}$ & 42 & 42 & 42 & 42 & 42 & 42 \\
\hline \multirow{3}{*}{$\begin{array}{c}\text { Number of } \\
\text { buildings with } \\
\text { different heights }\end{array}$} & Pearson Correlation &, $606^{*}$ &,$- 720^{*}$ & 1,000 &, $612^{*}$ &, $484^{*}$ & ,531* \\
\hline & Sig. (2-tailed) &, 000 &, 000 & &, 000 &, 001 &, 000 \\
\hline & $\mathrm{N}$ & 42 & 42 & 42 & 42 & 42 & 42 \\
\hline \multirow{3}{*}{$\begin{array}{c}\text { Intersection of } \\
\text { furniture elements } \\
\text { with skyline }\end{array}$} & Pearson Correlation & $428^{*}$ &,$- 758^{*}$ & ,612* & 1,000 &, $407^{*}$ & ,561* \\
\hline & Sig. (2-tailed) &, 005 &, 000 &, 000 & &, 007 &, 000 \\
\hline & $\mathrm{N}$ & 42 & 42 & 42 & 42 & 42 & 42 \\
\hline \multirow{3}{*}{$\begin{array}{l}\text { Intersection of } \\
\text { landscape with } \\
\text { skyline }\end{array}$} & Pearson Correlation & ,352 &,$- 586^{*}$ & $484^{*}$ & $407^{*}$ & 1,000 & ,642* \\
\hline & Sig. (2-tailed) &, 022 &, 000 & 001 &, 007 & &, 000 \\
\hline & $\mathrm{N}$ & 42 & 42 & 42 & 42 & 42 & 42 \\
\hline \multirow{3}{*}{$\begin{array}{l}\text { Skyline's fractal } \\
\text { dimension }\end{array}$} & Pearson Correlation & ,648* &,$- 816^{*}$ & ,531* &, $561^{*}$ & ,642* & 1,000 \\
\hline & Sig. (2-tailed) &, 000 &, 000 &, 000 &, 000 &, 000 & \\
\hline & $\mathrm{N}$ & 42 & 42 & 42 & 42 & 42 & 42 \\
\hline
\end{tabular}

*. Correlation is significant at the 0.01 level (2-tailed).

According to correlation coefficients, there are significant relationships between the fractal dimensions of the skylines and street characteristics at $p<0,01$ significance level with different coefficients. There are significant and positive correlations between "Number of peak points on building roofs", "Number of buildings with different heights", "Intersection of furniture elements with skyline", "Intersection of landscape with skyline" as independent variables and "Skyline's fractal dimension" as the dependent variable at $\mathrm{p}<0,01$ significance level statistically. Also, there is a significant and negative correlation between "Enclosure ratio of street" and "Skyline's fractal dimension" at $p<0,01$ significance level statistically, and the correlation coefficient was calculated as $-0,816$. According to the correlation result, the Pearson correlation coefficients and the impact level of characteristics on the skyline's fractal dimension are shown in Figure 6. 


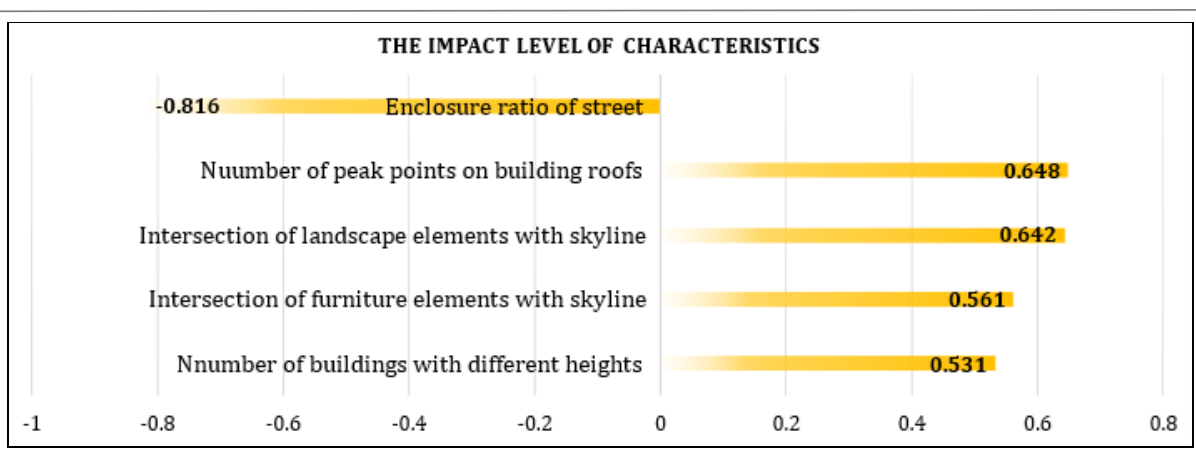

As a result, there is a strong negative correlation between the enclosure ratio of the streets and the complexity of the street skyline.

\section{Regression analysis}

After examining the effects of independent variables on the dependent variables, one by one with correlation analysis, the effect of the independent variables on the dependent variable was examined altogether with multiple regression analysis. According to ANOVA test, the regression model is statistically significant at $\mathrm{P}<0,05$ level $(\mathrm{F}=21.350)$ and the regression model explains $71 \%$ of the independent variables in predicting skyline's fractal dimensions at $\mathrm{P}<0.05$ significant level $(\mathrm{R} 2=0,71)$.

Table 7. The result of regression analysis

\begin{tabular}{|c|c|c|c|c|c|c|c|}
\hline \multicolumn{8}{|c|}{ Coefficients $^{\mathrm{a}}$} \\
\hline & \multirow{4}{*}{$\mathrm{B}$} & \multirow{4}{*}{$\begin{array}{l}\text { Std. } \\
\text { Error }\end{array}$} & \multirow{4}{*}{ Beta } & \multirow{4}{*}{$\mathrm{t}$} & \multirow{4}{*}{ Sig. } & \multirow{2}{*}{\multicolumn{2}{|c|}{$\begin{array}{c}95.0 \% \\
\text { Confidence } \\
\text { Interval for B }\end{array}$}} \\
\hline & & & & & & & \\
\hline & & & & & & Lower & Upper \\
\hline & & & & & & Bound & Bound \\
\hline (Constant) & 1.195 & .112 & & 10.635 & .000 & .967 & 1.423 \\
\hline $\begin{array}{c}\text { Number of peak points on } \\
\text { building roofs }\end{array}$ & .037 & .015 & .287 & 2.482 & $.018^{*}$ & .007 & .067 \\
\hline Enclosure ratio of street & -.080 & .017 & -.821 & -4.721 & $.000^{*}$ & -.115 & -.046 \\
\hline $\begin{array}{l}\text { Number of buildings with } \\
\text { different heights }\end{array}$ & .036 & .014 & .325 & 2.527 & $.016^{*}$ & .007 & .064 \\
\hline $\begin{array}{l}\text { Intersection of furniture } \\
\text { elements with skyline }\end{array}$ & -.013 & .022 & -.078 & -.587 & .561 & -.058 & .032 \\
\hline $\begin{array}{l}\text { Intersection of landscape with } \\
\text { skyline }\end{array}$ & .028 & .018 & .167 & 1.590 & .121 & -.008 & .064 \\
\hline
\end{tabular}

a. Dependent Variable: Skyline's fractal dimension

*. Correlation is significant at the 0.05 level

According to the result of regression analysis, As the number of buildings with different heights on the street and the mobility of buildings roofs increase, the fractal dimension and complexity of the street skyline increases. However, as the enclosure ratio of the street increases, the fractal dimension of the street skyline decreases.

\section{DISCUSSION}

It has been determined that the enclosure ratio of the street has a negative effect on the complexity of the street skyline. As the enclosure
Figure 6. The impact level of characteristics 
Examining the Relationship Between Enclosure Ratio of Street and Skyline's Complexity

ratio of the street increases, the complexity of the street skyline decreases.

According to Figure 7, as the enclosure ratio increases from $1: 2$ to $4: 1$, the complexity in the skyline, thus the perceptibility and visual quality of the street, decreases.

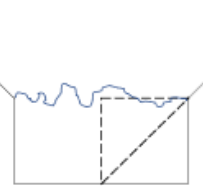

1:2

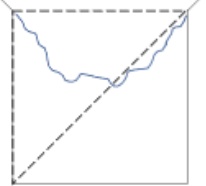

1:1

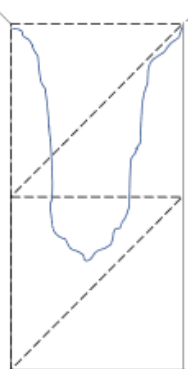

2:1

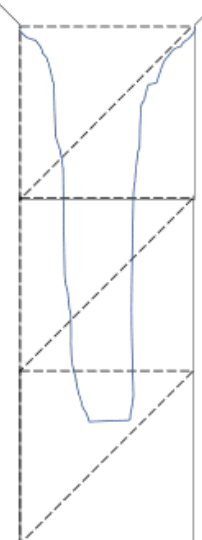

3:1

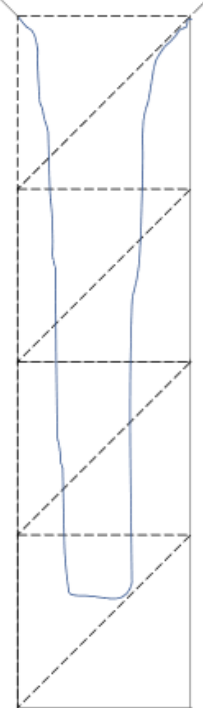

$4: 1$
Figure 7. Comparison of enclosure ratio and skyline's complexity
As the level of enclosure ratio of the street increases, the complexity of the skyline decreases, thus the visual perception and quality are weakened.

\section{CONCLUSIONS}

To design livable and desired cities, answering how people perceive urban spaces and revealing the factors that affect this perception are of great importance. The most important part of spatial perception is visual perception. In this context, the visual quality of the space and its effect on the perceptual process stands out as a critical issue. Visual quality is directly related to perceptual urban design principles. Visual quality is high in spaces designed with a high visual perceptibility. "Enclosure" and "Complexity" are two urban design principles that significantly affect the perceptibility of space. The fractal method is used as an objective and, at the same time, perceptual evaluation method to assess complexity in urban spaces. However, the perceptual evaluation of the enclosure in the space is realized only by subjective methods. This study aimed to perceptually evaluate the enclosure ratio of the street through the complexity of the street skyline with the fractal method. For this, street images from London and Chicago cities were analyzed. First, the street skylines were determined on the images, and then the fractal dimensions of the skylines were calculated. After that, the enclosure ratio of the streets was calculated quantitatively, and its relation with the fractal dimensions of the street skylines was evaluated. According to the result, as the enclosure ratio of the street increased, the fractal dimension of the 
street skyline decreased. As the enclosure ratio increases from 1:2 to 4:1, the complexity in the skyline, thus the perceptibility and visual quality of the street, decreases. In urban design studies, it is essential to reveal information about what factors increase the visual quality and perceptibility of streets. This study offered an objective and perceptual evaluation method in assessing the enclosure ratio of streets. Also, defining the enclosure ratio at an optimal ratio in street design will increase the visual complexity of the street skyline, thus increasing the visual quality and perceptibility of the street.

\section{FINANCIAL DISCLOSURE}

The authors declared that this study has received no financial support.

\section{CONFLICT OF INTEREST}

No conflict of interest was declared by the authors.

\section{ETHICS COMMITTEE APPROVAL}

Ethics committee approval was not required for this article.

\section{LEGAL PUBLIC/PRIVATE PERMISSIONS}

In this research, the necessary permissions were obtained from the relevant participants (individuals, institutions and organizations) during the survey, in-depth interview, focus group interview, observation or experiment.

\section{REFERENCES}

Akdağ, S. G., \& Bostancl, S. H. (2013). The Impacts of Prestıge Projects on The Skyline of Istanbul. International Journal of Architectural Research, Archnet-IJAR, 7(2), 269-281.

https://doi.org/https://doi.org/10.26687/ARCHNET-IJAR.V7I2.170

Alexander, C., Ishikawa, S., \& Silverstein, M. (1977). A Pattern Language: Towns, Buildings, Construction a Pattern Language. Oxford University Press.

Altaban, Ö. (2013). From Town Planning to Urban Design Work-The Dimensions to be Considered. ICONARP International Journal of Architecture, 1(1), 2-21.

Aslan, F., \& Atik, A. (2015). Perceptions About Commercial advertising Signs on Street Landscape and shopping Preferences: The sample of Kisla Street, Malatya- Turkey. American Journal of Psychology and Behavioral Sciences, 2(4), 129-140.

Barratt, K. (1980). Logic and Design, Revised: In Art, Science, and Mathematics. The Pitman Press.

Batty, M., \& Longley, P. (1994). Labratories for Visualizing Urban Form. In Fractal Cities: A Geometry of Form and Function (pp. 130-163). Academic Press Limited.

Berlyne, D. E. (1970). Novelty, Complexity, and Hedonic Value. Perception \& Psychophysics, 8(5), 279-286. https://doi.org/10.3758/BF03212593 
Examining the Relationship Between Enclosure Ratio of Street and Skyline's Complexity

Blizek, W., \& Berlyne, D. E. (1973). Aesthetics and Psychobiology. The Journal of Aesthetics and Art Criticism, 31(4), 553.

https://doi.org/10.2307/429334

Bostancl, S. H., \& Ocakçi, M. (2011). Innovative Approach to Aesthetic Evaluation Based on Entropy. European Planning Studies, 19(4), 705-723. https://doi.org/10.1080/09654313.2011.548473

Bostancl, S. H., \& Oral, M. (2017). Experimental Approach on the Cognitive Perception of Historical Urban Skyline. ICONARP International Journal of Architecture \& Planning Received, 5, 45-59. https://doi.org/10.15320/ICONARP.2017.25-E-ISSN

Burden, E. (1994). Elements of Architectural Design: A Visual Resource. Wiley.

Carmona, M., Heath, T., Oc, T., \& Tiesdell, S. (2003). Public Places- Urban Spaces; The Dimensions of Urban Design. Architectural Press.

Chalup, S. K., Henderson, N., Ostwald, M. J., \& Wiklendt, L. (2009). Architectural Science Review a Computational Approach to Fractal Analysis of a Cityscape's Skyline. Taylor \& Francis, 52(2), 126-134. https://doi.org/10.3763/asre.2009.0015

Ching, F. D. K. (2014). Architecture: Form, Space, \& Order. Wiley.

Cooper, J. (2003). Fractal Assessment of Street-Level Skylines a Possible Means of Assessing and Comparing Character. Urban Morphology, 7(2), 73-82.

Cooper, J., \& Oskrochi, R. (2008). Fractal Analysis of Street Vistas: A Potential Tool for Assessing Levels of Visual Variety in Everyday Street Scenes. Environment and Planning B Planning and Design, 35(2), 349-363. https://doi.org/10.1068/b33081

Cutting, J. E., \& Garvin, J. J. (1987). Fractal Curves and Complexity. Perception \& Psychophysics, 42(4), 365-370.

https://doi.org/10.3758/BF03203093

Denis, M., \& Fernandez, G. (2014). The Processing of Landmarks in Route Directions. In Representing space in cognition: interrelations of behavior, language, and formal models (pp. 42-55). Oxford University Press. https://doi.org/10.1093/acprof:oso/9780199679911.003.0004

Ewing, R., \& Handy, S. (2009). Measuring the Unmeasurable: Urban Design Qualities Related to Walkability. Journal of Urban Design, 14(1), 65-84. https://doi.org/10.1080/13574800802451155

Ewing, R., King, M. R., Raudenbush, S., \& Clemente, O. J. (2005). Turning Highways into Main Streets: Two Innovations in Planning Methodology. Journal of the American Planning Association, 71(3), 269-282.

https://doi.org/10.1080/01944360508976698

Gehl, J. (2010). Cities for People. Island Press.

Gehl, J., Kaefer, L. J., \& Reigstad, S. (2006). Close encounters with buildings. Urban Design International, 11(1), 29-47.

https://doi.org/10.1057/palgrave.udi.9000162

Groat, L. (1982). Meaning in Post-Modern Architecture: An Examination Using the Multiple Sorting Task. Journal of Environmental Psychology, 2(1), 3-22. https://doi.org/10.1016/S0272-4944(82)80002-9 
Gunawardena, G. M. W. L., Kubota, Y., \& Fukahori, K. (2015). Visual Complexity Analysis Using Taxonomic Diagrams of Figures and Backgrounds in Japanese Residential Streetscapes. Urban Studies Research, 2015, 1-12. https://doi.org/10.1155/2015/173862

Hagerhall, C. M., Purcell, T., \& Taylor, R. (2004). Fractal Dimension of Landscape Silhouette Outlines as a Predictor of Landscape Preference. Journal of Environmental Psychology, 24(2), 247-255. https://doi.org/10.1016/j.jenvp.2003.12.004

Hall, P. (2014). Cities of Tomorrow: an Intellectual History of Urban Planning and Design Since 1880. Wiley-Blackwell.

Heath, T., Smith, S. G., \& Bill, L. (2000). Tall Buildings and the Urban Skyline, the Effect of Visual Complexity on Preferences. Environment and Behavior, 32(4), 541-556. https://doi.org/10.1177/00139160021972658

Jacobs, A. (1993). Great Streets. MIT Press.

Jacobs, A., \& Appleyard, D. (1987). Toward an Urban Design Manifesto. Journal of the American Planning Association, 53(1), 112-120. https://doi.org/10.1080/01944368708976642

Jacobs, J. (1961). The Death and Life of Great American Cities. Vintage Books.

Jiang, S., \& Liu, D. (2013). Box-Counting Dimension of Fractal Urban Form. International Journal of Artificial Life Research, 3(3), 41-63. https://doi.org/10.4018/jalr.2012070104

Kahraman, E. Duygu, \& Cubukcu, E. (2017). Developing The Standards For Sense of Enclosure: An Experimental Study in Virtual Environments. CPUD 17 International City Planning and Urban Design Conference.

Kalın, A., \& Yılmaz, D. (2012). A Study on Visibility Analysis of Urban Landmarks: The Case of Hagia Sophia (Ayasofya) in Trabzon. METU Journal of the Faculty of Architecture, 29(1), 241-271. https://doi.org/10.4305/METU.JFA.2012.1.14

Kaplan, R., Kaplan, S., \& Ryan, R. (1998). With People in Mind: Design And Management Of Everyday Nature. Island Press.

Kaplan, S., Kaplan, R., \& Wendt, J. S. (1972). Rated Preference and Complexity for Natural and Urban Visual Material. Perception \& Psychophysics, 12(4), 354-356. https://doi.org/10.3758/BF03207221

Katz, P., Bressi, T. W., \& Scully, V. (1996). The New Urbanism: Toward an Architecture of Community. McGraw-Hill.

Li, J., Du, Q., \& Sun, C. (2009). An Improved Box-Counting Method for Image Fractal Dimension Estimation. Pattern Recognition, 42(11), 24602469. https://doi.org/10.1016/j.patcog.2009.03.001

Lynch, K. (1981). A Theory of Good City Form. MIT Press.

Mandelbrot, B. B. (1982). The Fractal Geometry of Nature. W.H. Freeman and Company.

Mesev, T. V., Longley, P. A., Batty, M., \& Xie, Y. (1995). Morphology From Imagery: Detecting and Measuring the Density of Urban Land Use. Environment \& Planning A, 27(5), 759-780. 
Examining the Relationship Between Enclosure Ratio of Street and Skyline's Complexity

https://doi.org/10.1068/a270759

Montgomery, J. (1998). Making a City: Urbanity, Vitality and Urban Design. Journal of Urban Design, 3(1), 93-116.

https://doi.org/10.1080/13574809808724418

Nasar, J. L. (1984). Visual Preferences in Urban Street Scenes: A CrossCultural Comparison Japon and United States. Journal of Cross-Cultural Psychology, 15(1), 79-93. https://doi.org/10.1177/0022002184015001005

Nasar, J. L. (1994). Urban Design Aesthetics: The Evaluative Qualities of Building Exteriors. Environment and Behavior, 26(3), 377-401. https://doi.org/10.1177/001391659402600305

Nasar, J. L., \& Terzano, K. (2010). The Desirability of Views of City Skylines After Dark. Journal of Environmental Psychology, 30(2), 215-225. https://doi.org/10.1016/j.jenvp.2009.11.007

Oostendorp, A., \& Berlyne, D. E. (1978). Dimensions in The Perception of Architecture: Identification And Interpretation of Dimensions of Similarity. Scandinavian Journal of Psychology, 19(1), 73-82. https://doi.org/10.1111/j.1467-9450.1978.tb00305.x

Peitgen, H.-O., Jürgens, H., \& Saupe, D. (1993). Chaos and Fractals, New Frontiers of Science. Springer-Verlag Press.

Pendola, R., \& Gen, S. (2008). Does "Main Street" Promote Sense of Community? A Comparison of San Francisco Neighborhoods. Environment and Behavior, 40(4), 545-574.

https://doi.org/10.1177/0013916507301399

Portella, A. A. (2007). Evaluating Commercial Signs in Historic Streetscapes: The Effects of the Control of Advertising and Signage on User's Sense of Environmental Quality. In Doctoral thesis. Oxford Brookes University.

Rapoport, A. (1977). Human Aspects of Urban Form: Towards a Man Environment Approach to Urban Form and Design. Pergamon Press.

Rapoport, A. (1990). The Meaning of the Built Environment: A Nonverbal Communication Approach. University of Arizona press.

Salingaros, N. A. (1999). Urban Space and Its Information Field. Journal of Urban Design, 4(1), 29-49.

https://doi.org/10.1080/13574809908724437

Salingaros, N. A. (2000). Complexity and Urban Coherence. Journal of Urban Design, 5(3), 291-316. https://doi.org/10.1080/713683969

Salingaros, N. A. (2010). Twelve Lectures on Architecture: Algorithmic Sustainable Design. Sustasis Press.

Shen, G. (2002). International Journal of Geographical Information Science Fractal dimension and fractal growth of urbanized areas. International Journal of Geographical Information Science, 16(5), 419437. https://doi.org/10.1080/13658810210137013

Spencer, D. (2009). Cities and Complexity: Understanding Cities with Cellular Automata, Agent-Based Models, and Fractals. The Journal of Architecture, 14(3), 446-450.

https://doi.org/10.1080/13602360903028044 
Stamps, A. E. (2000). Psychology and the Aesthetics of the Built Environment. Kluwer Academic Publishers Group. https://doi.org/10.1007/978-1-4757-6326-3

Stamps, A. E. (2002). Fractals, Skylines, Nature and beauty. Landscape and Urban Planning, 60(3), 163-184. https://doi.org/10.1016/S01692046(02)00054-3

Stamps, A. E. (2003). Advances in Visual Diversity and Entropy. Environment and Planning B: Planning and Design, 30(3), 449-463. https://doi.org/10.1068/b12986

Stamps, A. E. (2004). Mystery, Complexity, Legibility and Coherence: A Meta-Analysis. Journal of Environmental Psychology, 24(1), 1-16. https://doi.org/10.1016/S0272-4944(03)00023-9

Sussman, A., \& Hollander, J. B. (2015). Cognitive Architecture: Designing for How We respond to the Built Environment. Routledge/Taylor \& Francis Group.

Taylor, R. P. (2006). Reduction of Physiological Stress Using Fractal Art and Architecture. Leonardo, 39(3), 245-251.

Trancik, R. (1986). Finding Lost Space: Theories of Urban Design. Van Nostrand Reinhold.

Tveit, M., Ode, A. ' , \& Fry, G. (2007). Key Concepts in a Framework for Analyzing Visual Landscape Character. Landscape Research, 31(3), 229255. https://doi.org/10.1080/01426390600783269

Val, G., Atauri, J. A., \& Lucio, J. V. (2006). Relationship Between Landscape Visual Attributes and Spatial Pattern Indices: A Test Study in Mediterranean Climate. Landscape and Urban Planning, 77(4), 393-407. https://doi.org/10.1016/j.landurbplan.2005.05.003

Venturi, R. (1977). Complexity and Contradiction in Architecture. Princeton University Press.

Xavier, S., \& Portella, A. (2012). Complexity and Order in Commercial Streetscapes: How to Maintain User's Satisfaction with Visual Quality in Contemporary Cities. In O. Romice, E. Edgerton, \& K. Thwaites (Eds.), Human Experience in the Natural and Built Environment: Implications for Research, Policy and Practice. University of Strathclyde.

Ye, Y., Li, D., \& Liu, X. (2018). How Block Density and Typology Affect Urban Vitality: An Exploratory Analysis in Shenzhen, China. Urban Geography, 39(4), 631-652.

https://doi.org/10.1080/02723638.2017.1381536

Zacharias, J. (2001). Path Choice and Visual Stimuli: Signs of Human Activity And Architecture. Journal of Environmental Psychology, 21(4), 341-352. https://doi.org/10.1006/jevp.2001.0225

Zmeškal, O., Veselý, M., Nežádal, M., \& Buchníček, M. (2001). Fractal Analysis of Image Structures. HarFA-Harmonic and Fractal Image Analysis, 1(1), 3-5.

\section{Resume}

Leila Akbarishahabi currently works at Cappadocia University, Department of Architecture and Planning, as an Assistant Prof. She received her B.Arch in 
Examining the Relationship Between Enclosure Ratio of Street and Skyline's Complexity

Surveying Engineering from Tabriz University. Earned her M.Sc. and PhD. degrees in Urban and Regional Planning from Gazi University. Her research interests are urban design and quantitative research models. 